\title{
Multiresistant Bacteria And CurRent Therapy - The ECONOMical Side of The Story
}

\author{
M. H. Wilke \\ Dr. Wilke GmbH - inspiring.health, Munich, Germany
}

\begin{abstract}
Severe infections with multiresistant bacteria (MRB) are a medical challenge and a financial burden for hospitals. The adequate antibiotic therapy is a key issue in multiresistant bacteria management. Several major cost drivers have been identified. Remarkably drug acquisition costs are not necessarily included. Most significant are the length of stay in hospital, the hours of mechanical ventilation and the time treated on an intensive care unit.

In a systematic review of the literature the following aspects were investigated:

- Do generic treatment strategies contribute in cost savings?

- Are there specific results for recent antibiotics?

Early adequate and effective antimicrobial treatment, switch from i.v. to oral therapy, adjusted duration of therapy and adherence to guidelines have been found to be successful strategies.

Looking at specific antibiotics, the best evidence for cost-effectiveness is found for Linezolid in treatment of cSSTI as well as in HAP. Daptomycin shows good economic results in bloodstream infections, so possibly being a cost-effective alternative to vancomycin. Looking at tigecycline the published data show neither higher costs nor savings compared to imipeneme. Doripenem as one of the newest therapy options has proven to be highly cost-saving in HAP when compared with imipenem. However, most analyses are based on pharmacoeconomic modelling rather than on directly analysing trial data or real life clinical populations.

Conclusion: Using modern antibiotics in whole is not more expensive than using established therapies. Modern antibiotics are cost-effective and sometimes even cost-saving. This is especially true if an effective therapy is initiated as early as possible.
\end{abstract}

Abbreviations:

ALOS $=$ Average length of stay in a given DRG, basis for determining whether a patient causes more costs than reimbursement

$\mathrm{CAP}=$ community acquired pneumonia

cSSTI $=$ complicated skin and soft tissue infections

DRG = diagnoses related groups, systems to classify patients based on their resource consumptions
HAP $=$ hospital acquired pneumonia

$\mathrm{HMV}=$ hours of mechanical ventilation

ICU-days $=$ treatment days on an intensive care unit

LOS = length of stay in hospital

$\mathrm{MRB}=$ infection with Multiresistant bacteria

\section{INTRODUCTION}

Severe MRB cause a serious burden of disease in most countries worldwide $[1,2,6,23]$. Their therapeutic management is a major cost driver in healthcare, particularly in hospitals. Looking at the economical impact of antibiotic therapy of severe MRB infections, several factors were identified as the major cost drivers [3-5]:

- prolonged hospital length of stay (LOS)

- hours of mechanical ventilation (HMV)

- duration of treatment on an intensive care unit (ICU)

- cost of patient isolation (isolation)

- complications, such as renal failure or infection transmission

Whether any given antibiotic therapy is an economically adequate option therefore depends on its effect on one or more of these cost drivers. Interestingly, the actual daily costs of the drug itself does not significantly affect the overall costs of treatment. Still in many settings, the choice of therapy is controlled by drug acquisition costs, as these data are easily available $[7,8]$.

This article provides a review of the current literature on the role of recent antibiotic agents in the treatment of MRB infections from the economical perspective.

\section{Materials AND METHODS}

We conducted a literature review to investigate the available evidence on cost-effectiveness of antibiotic treatment strategies in the management of MRB infections. Looking at the economical impact of antibiotic therapy in general, there are the following factors that have been proven to influence positively the abovementioned cost drivers: 
Influencing factor

Early adequate first-line antibiotic therapy

IV-to-oral switch

IV-to-oral switch

Effect on cost driver

Ref.

Shorter duration of therapy

Early transfer from ICU to normal ward

Shorter LOS

Less complications

Shorter i.v. therapy

Earlier discharge and outpatient treatment

[14-17]

Adjusted duration of therapy

Less adverse events

Less selection of resistance

Less drug cost

Shorter LOS

Adherence to guidelines

Shorter duration of therapy

Shorter LOS

Less complications

Less ICU admissions

Less HMV

$[7,24,25]$

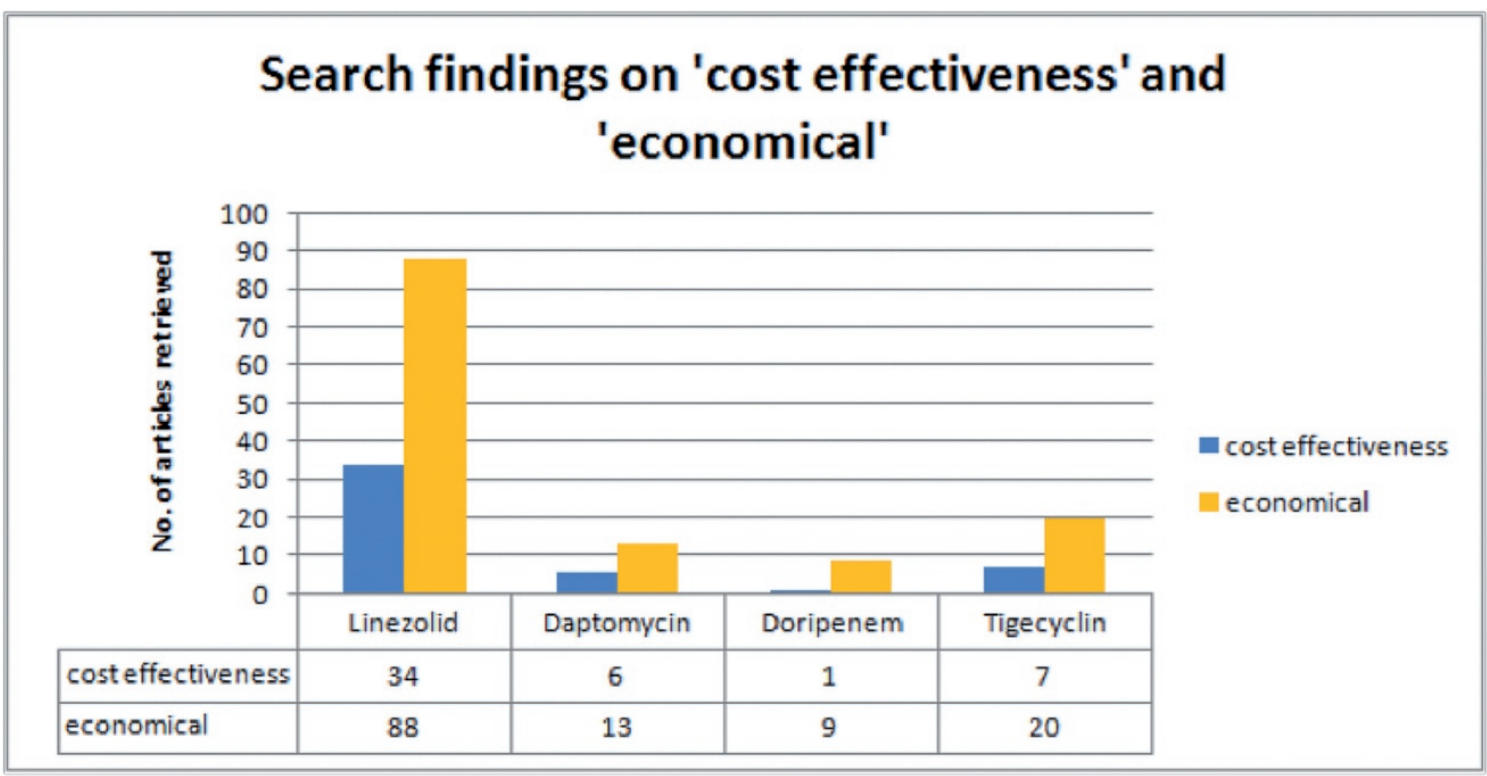

Fig. 1.

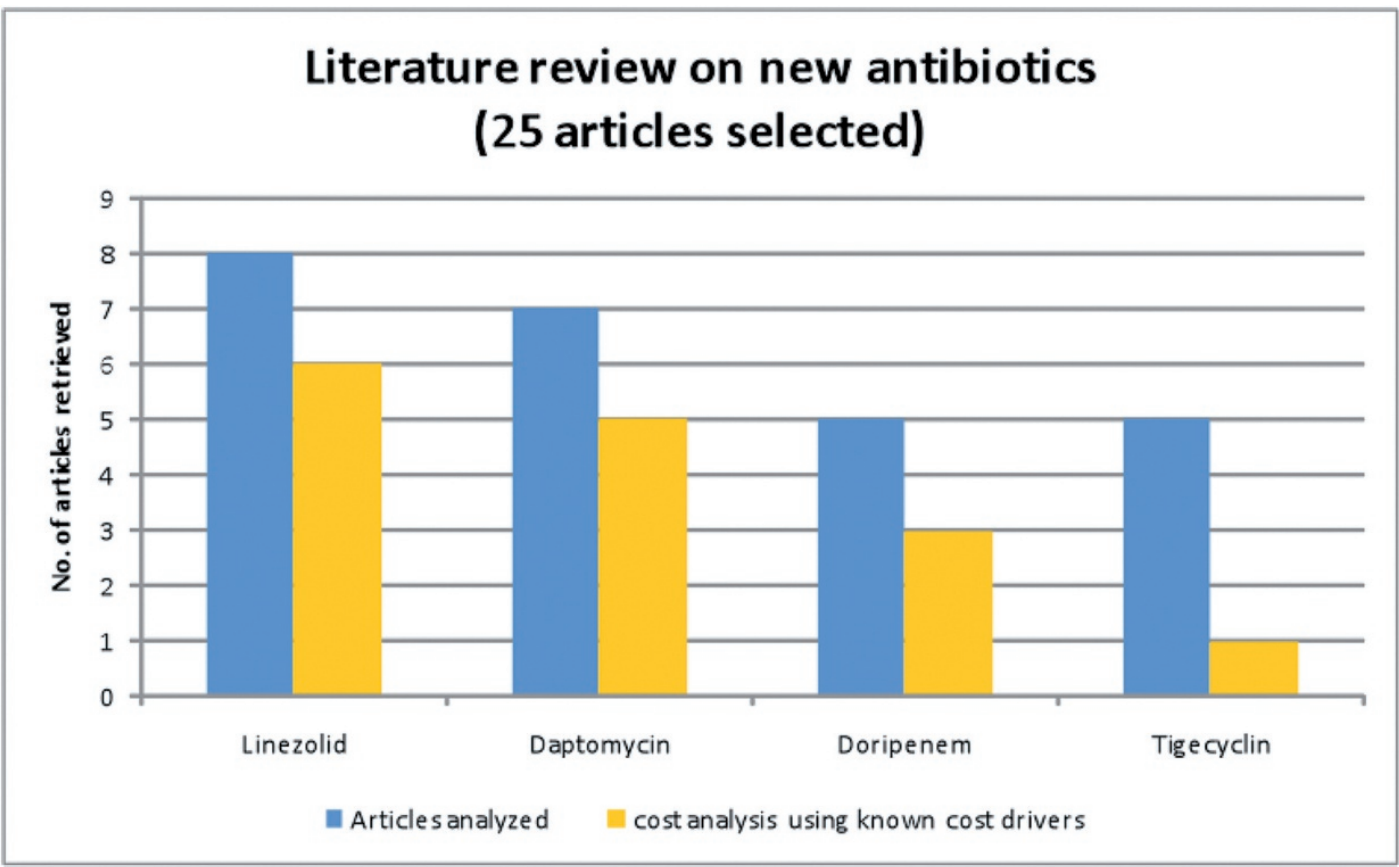

Fig. 2.

Literature review on 25 selected publications on new antibiotics. 
With respect to these known factors affecting major cost drivers, we conducted a literature review focussed on articles dealing with recently introduced antibiotics active against MRB in the context of cost issues or cost-impacting factors.

We used the agent AND 'cost-effectiveness' OR 'economical' as search terms.

\section{RESULTS}

We had 178 search findings in total. Figure 1 shows the search findings.

The number of publications referring explicitely to cost-effectiveness or economical analyses on linezolid is the highest. For closer analysis we then picked 25 articles that focussed on one or more of our above mentioned cost drivers.

In general economical analyses for drugs often differ from clinical trials. The most common method is modelling economical effects by using results from clinical trials. Only rarely economical data are directly collected in the course of clinical trials. Nearly no data exist on economical analyses based on clinical routine treatment.

Figure 2 shows the results of the 25 articles closely reviewed.

In the following section we describe major findings for the agents in focus.

\section{LINEZOLID}

Multiple economic analyses for linezolid have been published over the last decade. There are publications for both major indications (cSSTI, HAP) and for several countries (USA, Germany, Spain, France). Thus the economics of linezolid use effects appear to be well investigated. Studies are either cost-effectiveness analyses based on data of clinical trials or pharmacoeconomic models [26-30]. The cost savings associated with the use of linezolid are predominantly due to a significant reduction of LOS. Among recent antibiotics used for MRB infection, linezolid is the only drug that is available intravenous (IV) and orally (with a similar dose/exposure ratio), and the IV-to-oral switch allows earlier hospital discharge. The net effect is most significant in the treatment of cSSTI $(2.0-2.3$ LOS days saved), as the overall severity of illness is lower than in pneumonia, and hospital-acquired pneumonia in particular. However, linezolid has been shown to be cost-effective in pneumonia as well. This is most likely due to earlier recovery and earlier hospital discharge. Most authors today acknowledge linezolid as a cost-effective component of the therapeutic armamentarium, particularly in MRSA infections [32]. However, this insight has not been entirely implemented in clinical practice yet [33].

There are no explicit analyses available for other cost drivers. Most recently, a meta-analysis [31] suggested that there is no specific economic rationale supporting the use of vancomycin versus linezolid for empiric therapy in settings with low MRSA prevalence.

\section{DAPTOMYCIN}

Introduced more recently than linezolid, daptomycin already prompted a substantial number of publications on economic issues and publications referring to significant cost drivers [34-40]. The most relevant indication for daptomycin is bloodstream infection with gram-positive cocci, as the overall number of patients is significantly higher than in endocarditis. Similar to most of the other drugs discussed here, daptomycin is also suitable for the treatment of cSSTI. The main economic impact of daptomycin is associated with a reduction of LOS. However, earlier transfer from ICU to general ward is also described. Some publications [35, 37-39] attribute lower costs to earlier cure and higher cure rates achieved with daptomycin versus vancomycin, which may relate to the bactericidal effect of the drug. However the trials underlying these analyses were no RCTs.

Daptomycin has been shown to be associated with less occurrence of renal failure than vancomycin [34]. It thus may be speculated that the lipopeptide antibiotic has a potential to influence positively the cost-driving duration of therapy as mentioned in one publication (39). However, this aspect still awaits further investigation.

\section{DORIPENEM}

Convincing economic analyses and articles referring to cost drivers in clinical studies have been published for doripenem, a recently approved carbapenem antibiotic [41-45]. Doripenem was shown to be associated with less resource use regarding LOS, HMV, and less complications (PsA resistance, PsA transmissions) compared to imipenem. No significant reduction in ICU days has been described so far. Remarkably, economical evaluation of this drug was included in the data and analysis of clinical trials.

\section{TigeCYCLINE}

Among the articles retrieved on tigecycline [46-51], there were two dedicated analyses that dealt with resource utilization (i.e. cost) associated with the use of this recently introduced glycylcyclin antibiotic [49]. Tigecycline is an interesting treatment option particularly in complicated intraabdominal infections. With its very broad spectrum of activity, tigecycline can be used empirically in suspected polymicrobial infections. Despite the slightly higher drug acquisition costs compared to imipenem it has been showed that first-line therapy is not more expensive than using tigecycline in second-line therapy [51]. It also has the potential to be used as a monotherapy in this indication [48] and therefore would affect overall costs by abolishing the need for another drug. Two publications explicitly report that LOS was not negatively affected when comparing tigecycline with imipenem [49, 50].

Table 1 summarizes the data indicating a positive influence of the drugs covered in this review on cost drivers and influencing factors. 
Table 1. Overview of potential economic effects of the reviewed antibiotics.

\begin{tabular}{lcccc}
\hline Parameter & Linezolid & Daptomycin & Doripenem & Tigecycline \\
\hline LOS & $\mathrm{X}$ & $\mathrm{X}$ & $\mathrm{X}$ & \\
HMV & & & $\mathrm{X}$ & \\
ICU days & & & \\
Isolation & & $\mathrm{X}$ & $(\mathrm{X})^{*}$ \\
Complications & & & $(\mathrm{X})$ \\
Early choice & $\mathrm{X}$ & $\mathrm{X})$ & $\mathrm{X}$ \\
IV-to-oral switch & $\mathrm{X}$ & & & \\
$\begin{array}{l}\text { Duration of therapy } \\
\text { Combination therapy }\end{array}$ & & & & \\
Adherence to guidelines & & & & \\
\hline
\end{tabular}

*Tigecycline may have positive effects on drug costs when used as monotherapy.

$\mathrm{X}=$ potential reduction of total treatment cost.

\section{DISCUSSION}

It appears that the number of publications that evaluate the economic impact of new antimicrobial agents such as linezolid, daptomycin, tigecycline and doripenem is increasing. For every substance there are results or at least trends that indicate favourable effects on economic outcomes. The studies uniformly show that despite higher drug acquisition costs for newer antibiotics, overall treatment costs can be lower or therapy is cost-effective due to other factors (i.e. survival for linezolid in pneumonia). Only a limited number of studies analyzed ,real-life' clinical populations [11-13, 24, 27, $28,37,39$, whereas the greater part of the publications used pharmacoeconomic models based on data from clinical trials. While this is a well-accepted approach, it does not prove the relevance of the respective findings in the clinical routine setting. Obviously, it is a most challenging task to validate data from pharmacoeconomic models in "real life", as the variance of patient characteristics is much higher than in trial population and various confounders complicate such analyses. There are some ongoing studies trying to relate DRG outcomes - i.e. the net effect on hospital reimbursement - to the chosen therapy strategies. It will be interesting to see the results in the near future.

\section{CONCLUSION}

The economic impact of antibiotic treatment choices in complicated infections with multiresistant bacteria is an increasingly important issue, as numerous publications document the enormous extra healthcare cost of these infections $(1,3,4,9,10,13,36,41)$. The analysis of the current literature shows that therapy with modern antibiotics is generally cost-effective and may even be associated with net savings although drug acquisition costs are higher in conventional therapy regimens. Currently, favourable cost effects are best documented for linezolid. A number of pharmacoeconomic analyses are also available for daptomycin, tigecyclin and doripenem, and more will certainly follow. Investigators may increasingly use economic data to document favourable cost effects of state-of-the-art therapy, thus overcoming the still wide-spread focus on ,price-tags'. However only a few analyses use 'reallife' clinical settings for cost analyses. Modelling is the most common and most accepted approach to gain 'economical evidence'. With directly connecting economical analyses to clinical trials and/or to routine data collections the results would reach a higher level of acceptance among hospital administrators.

Clinicians, pharmacists and economists in the hospital should work together to realize cost-savings with effective antibiotic therapy rather than sticking to treatment choices driven by drug acquisition cost.

\section{REFERENCES}

1. Köck R et.al, Methicillin-resistant Staphylococcus aureus (MRSA): burden of disease and control challenges in Europe, Euro Surveill. 2010 Oct 14;15(41):19688

2. Schweickert B et.al, The MRSA-Import in ICUs is an important predictor for the occurrence of nosocomial MRSA-cases, Clin Microbiol Infect. 2010 Oct 26. doi: 10.1111/j.1469-0691.2010.03409.x. [Epub ahead of print]

3. Resch A, Wilke M, Fink C; The cost of resistance: incremental cost of methicillin-resistant Staphylococcus aureus (MRSA) in German hospitals; Eur J Health Econ. 2009 Mar;10(1):287-97

4. Wernitz MH, Lenz C, Veit SK. Die Bedeutung von Infektionen durch multiresistente Staphylococcus aureus für das deutsche Gesundheitswesen - The (n)ever ending story? J Pharmakol Ther 2009:18;75-82

5. Ott E et.al, Costs of nosocomial pneumonia caused by meticillin-resistant Staphylococcus aureus, J Hosp Infect. 2010 Oct 14. [Epub ahead of print]

6. Filice GA, Excess costs and utilization associated with methicillin resistance for patients with Staphylococcus aureus infection, Infect Control Hosp Epidemiol. 2010 Apr;31(4):365-73

7. Dietrich ES, Berthold H, Jopp R, Schreier U, Gilge R, Bartmann P. Kosten einer leitli-niengerechten Arzneimitteltherapie in Deutschland. Gesundh ökon Qual manag 2005; 10: 35-43

8. Dietrich ES, Schmid M, Bucher A, Lemmen S, Frank U, Daschner FD. Kostenreduktion in der Antibiotika-Therapie. Krankenhauspharmazie 1998;19(6):287-92

9. Slama TG, Gram-negative antibiotic resistance: there is a price to pay, Crit Care. 2008;12 Suppl 4:S4. Epub 2008 May 21 
10. Eandi M; Hospital management of complicated intra-abdominal infections: pharmacoeconomic evaluation.; J Chemother. 2009 Jul;21 Suppl 1:44-55

11. Kumar A et.al, Duration of hypotension before initiation of effective antimicrobial therapy is the critical determinant of survival in human septic shock.; Crit Care Med. 2006 Jun;34(6):1589-96

12. Vallés J, Rello J, Ochagavía A, Garnacho J, Alcalá MA; Community-acquired bloodstream infection in critically ill adult patients: impact of shock and inappropriate antibiotic therapy on survival.; Chest. 2003 May;123(5):1615-24

13. Rello J, Determinants of Choice and Prescription Patterns in Empiric Antibiotic Therapy for HAP/VAP, Eur Respir J. 2010 Sep 16. [Epub ahead of print]

14. Ballock RT, Newton PO, Evans SJ, Estabrook M, Farnsworth CL, Bradley JS; A comparison of early versus late conversion from intravenous to oral therapy in the treatment of septic arthritis.J Pediatr Orthop. 2009 Sep;29(6):636-42

15. Eachempati SR, Hydo LJ, Shou J, Barie PS ; Does de-escalation of antibiotic therapy for ventilator-associated pneumonia affect the likelihood of recurrent pneumonia or mortality in critically ill surgical patients?; J Trauma. 2009 May;66(5):1343-8

16. Mertz D, Koller M, Haller P, Lampert ML, Plagge H, Hug B, Koch G, Battegay M, Flückiger U, Bassetti S; Outcomes of early switching from intravenous to oral antibiotics on medical wards.; J Antimicrob Chemother. 2009 Jul;64(1):188-99

17. Rhew DC, Tu GS, Ofman J, Henning JM, Richards MS, Weingarten SR; Early switch and early discharge strategies in patients with community-acquired pneumonia: a metaanalysis.; Arch Intern Med. 2001 Mar 12;161(5):722-7

18. Brady PW, Conway PH, Goudie A, Length of intravenous antibiotic therapy and treatment failure in infants with urinary tract infections, Pediatrics. 2010 Aug;126(2): 196-203. Epub 2010 Jul 12

19. Schuetz P et.al, Effect of procalcitonin-based guidelines vs standard guidelines on antibiotic use in lower respiratory tract infections: the ProHOSP randomized controlled trial JAMA. 2009 Sep 9;302(10):1059-66.

20. Hochreiter M et.al, Procalcitonin to guide duration of antibiotic therapy in intensive care patients: a randomized prospective controlled trial, Crit Care. 2009;13(3):R83. Epub 2009 Jun 3

21. Chastre J et.al, Comparison of 8 vs 15 days of antibiotic therapy for ventilator-associated pneumonia in adults: a randomized trial, JAMA. 2003 Nov 19;290(19):2588-98

22. Micek ST et.al, Optimizing antibiotic treatment for ventilator-associated pneumonia, Pharmacotherapy. 2006 Feb; 26(2):204-13

23. Van Zanten ARH, Engelfriet PM, van Dillen K, van Veen M, Nuijten MJC, Poldermann KH. Importance of nondrug costs of intravenous antibiotic therapy. Critical Care 2003; 7: 420-21. Cousins D: Improving safe medication practice. NHS National Patient Safety Agency. www.npsa.nhs.uk

24. Menendez R, Reyes S, Martinez R, de la CP, Manuel VJ, Vallterra J. Economic evaluation of adherence to treatment guidelines in nonintensive care pneumonia. Eur Respir J 2007 Apr;29(4):751-6.

25. Shorr AF et.al, Impact of antibiotic guideline compliance on duration of mechanical ventilation in critically ill patients with community-acquired pneumonia, Chest. 2006 Jul;130(1):93-100

26. Shorr AF, Susla GM, Kollef MH. Linezolid for treatment of ventilator-associated pneumonia: a cost-effective alternative to Vancomycin. Crit Care Med. 2004 Jan;32(1): $137-43$.

27. Mullins CD, Hsu VD, Shorr A et al. Linezolid versus Vancomycin health and economic outcomes: a retrospec- tive database study of 11,018 infection-related hospitalization treatment episodes. ECCMID 2009; Poster P-778.

28. McCollum M, Rhew DC, Parodi S; Cost analysis of switching from i.v. vancomycin to p.o. linezolid for the management of methicillin-resistant Staphylococcus species.; Clin Ther. 2003 Dec;25(12):3173-89

29. Schürmann D, Sorensen SV, De Cock E, Duttagupta S, Resch A; Cost-effectiveness of linezolid versus vancomycin for hospitalised patients with complicated skin and soft-tissue infections in Germany.; Eur J Health Econ. 2009 Feb;10(1):65-79

30. Grau S, Rubio-Terrés C, Pharmacoeconomics of linezolid, Expert Opin Pharmacother. 2008 Apr;9(6):987-1000

31. Walkey AJ, O'Donnell MR, Wiener RS, Linezolid versus Glycopeptide Antibiotics for the Treatment of Suspected Methicillin-Resistant Staphylococcus Aureus Nosocomial Pneumonia: A Meta-Analysis of Randomized Controlled Trials, Chest. 2010 Sep 23. [Epub ahead of print]

32. Shorr AF, Epidemiology and economic impact of meticillin-resistant Staphylococcus aureus: review and analysis of the literature, Pharmacoeconomics. 2007;25(9):75168

33. Boldt J, Papsdorf M, Expensive modern therapy options in intensive care medicine in Germany-- are they being used? Results of a questionnaire, Dtsch Med Wochenschr. 2005 Jan 21;130(3):87-91

34. Fowler V et.al, Daptomycin versus standard therapy for bacteremia and endocarditis caused by Staphylococcus aureus, N Engl J Med. 2006 Aug 17;355(7):653-65.

35. Seaton RA, Daptomycin: rationale and role in the management of skin and soft tissue infections, J Antimicrob Chemother. 2008 Nov;62 Suppl 3:iii15-23

36. Lodise TP Jr, McKinnon PS, Burden of methicillin-resistant Staphylococcus aureus: focus on clinical and economic outcomes, Pharmacotherapy. 2007 Jul;27(7):100112

37. Krige JE, Effectiveness and duration of daptomycin therapy in resolving clinical symptoms in the treatment of complicated skin and skin structure infections, Curr Med Res Opin. 2007 Sep;23(9):2147-56

38. Davies SL, Daptomycin versus vancomycin for complicated skin and skin structure infections: clinical and economic outcomes, Pharmacotherapy. 2007 Dec;27(12): 1611-8.

39. Fossaceca C, Outcomes analysis of daptomycin use in a community hospital, Adv Ther. 2007 May-Jun;24(3):51728

40. Bhavnani SM et.al, Cost-Effectiveness of daptomycin versus vancomycin and gentamicin for patients with methicillin-resistant Staphylococcus aureus bacteremia and/or endocarditis, Clin Infect Dis. 2009 Sep 1;49(5): 691-8

41. Amin A, Clinical and economic consequences of ventilator-associated pneumonia, Clin Infect Dis. 2009 Aug 15;49 Suppl 1:S36-43

42. Merchant S et.al, Hospital resource utilization with doripenem versus imipenem in the treatment of ventilator-associated pneumonia, Clin Ther. 2008 Apr;30(4):71733

43. Chastre J et.al, Efficacy and safety of intravenous infusion of doripenem versus imipenem in ventilator-associated pneumonia: a multicenter, randomized study, Crit Care Med. 2008 Apr;36(4):1089-96.

44. Matthews SJ, Lancaster JW, Doripenem monohydrate, a broad-spectrum carbapenem antibiotic, Clin Ther. 2009 Jan;31(1):42-63

45. Kollef MH, Nathwani D, Merchant S, Gast C, Quintana A, Ketter N, Medical resource utilization among patients with ventilator-associated pneumonia: pooled analysis of randomized studies of doripenem versus comparators, Crit Care. 2010;14(3):R84. Epub 2010 May 10 
46. Doan TL et al., Tigecycline: a glycylcycline antimicrobial agentClin Ther. 2006 Aug;28(8):1079-106

47. Nicolau DP, Management of complicated infections in the era of antimicrobial resistance: the role of tigecycline, Expert Opin Pharmacother. 2009 May;10(7):1213-22

48. Reygaert WC, Antibiotic optimization in the difficult-totreat patient with complicated intra-abdominal or complicated skin and skin structure infections: focus on tigecycline, Ther Clin Risk Manag. 2010 Sep 7;6:419-30

49. Mallick R, Sun S, Schell SR, Predictors of efficacy and health resource utilization in treatment of complicated intra-abdominal infections: evidence for pooled clinical studies comparing tigecycline with imipenem-cilastatin, Surg Infect (Larchmt). 2007 Apr;8(2):159-72

50. Bergallo C et.al, Safety and efficacy of intravenous tigecycline in treatment of community-acquired pneumonia: results from a double-blind randomized phase 3 comparison study with levofloxacin, Diagn Microbiol Infect Dis. 2009 Jan;63(1):52-61
51. Ancona F, Economic impact simulation analysis of use of tigecycline, as appropriate, in first-course antibiotic therapy for complicated intra-abdominal infections in intensive care patients, Minerva Med. 2010 Oct;101(5): $319-8$

Received: October 24, 2010 / Accepted: November 12, 2010

Address for correspondence:

Dr. Wilke GmbH - inspiring.health

Joseph-Wild-Str. 13

81829 München

Germany

Tel.: $\quad+49(8) 89-18908376-0$

Fax: $\quad+49(8) 89-18908376-9$

E-mail: michael.wilke@d-w-g.de 